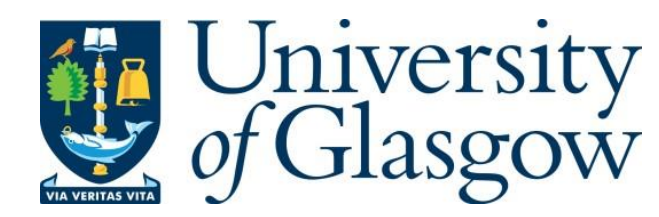

Deli, Y. D. (2016) Endogenous capital depreciation and technology shocks. Journal of International Money and Finance, 69, pp. 318-338.

There may be differences between this version and the published version. You are advised to consult the publisher's version if you wish to cite from it.

http://eprints.gla.ac.uk/135958/

Deposited on: 1 March 2017

Enlighten - Research publications by members of the University of Glasgow http://eprints.gla.ac.uk 


\title{
Endogenous Capital Depreciation and Technology Shocks*
}

\author{
Yota D. Deli ${ }^{\dagger}$ \\ ESRI, Trinity College Dublin
}

August 10, 2016

\begin{abstract}
I examine the dynamic impact of capital maintenance on key aggregates through the depreciation rate. I find that two factors are crucial for the short-run effects of Total Factor Productivity and Investment-Specific shocks: i) the marginal efficiency of maintenance and its connection with the rate of utilization, and ii) the interplay between the intertemporal effect of maintenance and the substitution effect between maintenance and utilization. The latter is expressed by the relative size of the elasticity of maintenance to the Hicksian elasticity of complementarity between maintenance and utilization. These theoretical results suggest that to match the observed responses of the macroeconomic aggregates the sign of the cross derivative should be negative and that the relative size of the Hicksian elasticity should be smaller than the maintenance elasticity of marginal depreciation. Finally, the model suggests that the main macroeconomic aggregates react procyclically, with the exception of maintenance, the behavior of which depends on the type of the shock.
\end{abstract}

Keywords: RBC, endogenous depreciation, maintenance, technology shocks.

JEL classification: E22, E32, E23, L10

${ }^{*}$ I am grateful to Sarantis Kalyvitis, Manthos D. Delis, Anastasios Xepapadeas, Iftekhar Hasan, two anonymous referees, Evi Pappa, Jordi Caballe, the macro-economy team of the Universitat Autonoma de Barcelona, and numerous seminar participants for useful comments.

${ }^{\dagger}$ Economic and Social Research Institute, Whitaker Square, Sir John Rogerson’s Quay, Dublin 2, Ireland. E-mail adress: yota.deli@gmail.com. 


\section{Introduction}

The depreciation rate of capital is an important component of capital accumulation. Despite the fact that several papers have shown the quantitative importance of capital maintenance (e.g. McGrattan and Schmitz, 1999), in most general equilibrium frameworks the depreciation rate of capital is assumed to be either exogenous or endogenous only to capital utilization (e.g. Greenwood et al., 1988). In this paper I build a standard real Business Cycle (RBC) model, where capital depreciation is endogenous to both capital utilization and capital maintenance and the cycle is driven both by Investment Specific (I-S) and Total Factor Productivity (TFP) technological shocks. This analysis is motivated by the facts that i) an assumption of endogenous capital depreciation that subsequently alters the decision of investment might highlight different mechanisms that drive the cycle, and ii) the I-S shock, which directly affects investment, may have different effects when capital depreciation is endogenous.

Capital utilization shows how intensively agents decide to use the existing capital stock, with a higher degree of utilization resulting in a higher depreciation rate. Maintenance, on the other hand, is the deliberate employment of resources in the form of labor, spare parts, and other materials to preserve the operative state of capital goods (Bitros, 1976) and is inversely related to the depreciation rate.

Capital utilization has been considered to play an important role on the comovements of the key macroeconomic aggregates during the economic cycle. Greenwood et al. (1988), in a framework with technological shocks that affect the efficiency of investment, were the first to conduct a comparative static analysis considering a depreciation rate endogenous to capital utilization. These shocks, known as Investment-Specific (I-S) technological change, alter the relative price of investment and represent a shift to the marginal efficiency of investment, directly affecting the productivity of new capital. In particular, the transmission mechanism is that an increase in the efficiency of newly produced investment goods stimulates the creation of new capital and the utilization of existing capital, and therefore accelerate the depreciation of "old capital". Although the role of capital utilization in generating economic dynamics has already been analyzed in several papers, there has been little attempt to capture the effects of maintenance on the business cycle. McGrattan and Schmitz (1999) highlight the quantitative importance of capital maintenance using data from Canada, by showing that maintenance and repair expenditures account for almost $6 \%$ of GDP.

Whelan (2002) examines the effects of a TFP shock and finds that an exogenous capital depreciation assumption leads to an under-estimation of depreciation, to a subsequent over-estimation of growth of capital, and to an under-estimation of TFP growth. Motivated by this result, I build a simple RBC model with endogenous capital depreciation. In particular, in this model I extend the work of Boucekkine et al. $(2003,2010)$ by introducing I-S shocks in a framework where capital depreciation is endogenous on capital utilization and capital maintenance. This is motivated by the fact that I-S shocks are the most important drivers of business cycle fluctuations in the US. Specifically, Justiniano et al. (2010) estimate that I-S shocks account for almost $60 \%$ of the variance of output and hours worked and for $80 \%$ of the variance of investment. 
Analytical results for the responses of the main macroeconomic aggregates following a TFP and an I-S shock are obtained, and I examine the factors that affect their response during the cycle, which arise from the substitutability/complementarity of investment, capital maintenance and, capital utilization. I then experiment with a framework where capital depreciation is endogenous either on maintenance or in utilization (but not in both), to address the finding of Jaimovich and Rebelo (2009) that capital utilization is a crucial component for an RBC framework to create the comovements of the key aggregates.

The paper contributes in three strands of the literature. First, the study reinforces the results of Boucekkine and Ruiz-Tamarit (2003) that the effects are highly related to the cross derivative of the capital depreciation function. In particular, when an I-S shock is considered, I find that, besides the sign of the cross derivative, the most important factor driving the results is the relative size of the maintenance elasticity of marginal depreciation compared to the Hicksian elasticity of complementarity between capital utilization and capital maintenance. I also find that even when these two relative sizes are equal, maintenance is the only variable that is affected by a technology shock. This finding stems from our assumption that capital maintenance is independent from the labor choice. ${ }^{1}$

This result is important because it allows identifying the assumptions to be used for the capital depreciation function stemming from the empirical behavior of this variable. Until now there has been no reason to a priori assume whether this cross derivative is negative or positive, and whether the relative size of maintenance elasticity is greater or not than the Hicksian elasticity of complementarity. Albonico et al. (2014) create the Canadian and US series for the depreciation rate, the maintenance and the capital utilization. Our theoretical results suggest that to match the observed responses of the macroeconomic aggregates the sign of the cross derivative should be negative and that the relative size of the Hicksian elasticity should be smaller than the maintenance elasticity of marginal depreciation. This means that i) an increase in capital utilization results to a decrease in the marginal efficiency of maintenance, and ii) the substitution effect between maintenance and capital utilization is smaller than the marginal maintenance effect.

Second, the findings of this paper strengthen the results of Greenwood et al. (1988) under specific forms for the depreciation rate function concerning the comovement of consumption, investment, and output. In particular the introduction of maintenance in an environment with I-S and TFP shocks, better explains the comovement of the macroeconomic aggregates during the cycle, since it provides a stronger channel to explain the positive correlation of consumption, investment, productivity of labor, and hours worked with output. Even in terms of the volatility of the aforementioned responses, it is shown that the incorporation of capital maintenance in the model reduces the variance of the Solow residuals needed to match the output volatility. This occurs because the I-S shock causes a reallocation between investment and capital maintenance that indirectly affects

\footnotetext{
${ }^{1}$ It could be assumed that maintenance is labor intensive and therefore the decisions for maintenance would be directly affected by the decisions for labor, but this would make an explicit comparative statics exercise intractable (for a numerical solution, see Collard and Kollintzas, 2000). As the present study already covers a lot of ground, I leave this exercise for future research.
} 
labor and capital, resulting to a change in the size of the Solow residuals. To this end, the paper suggests that maintenance should always be incorporated in a model with endogenous depreciation.

Third, one of the most important results of the paper arises from the response of capital maintenance to an I-S or a TFP shock. The interesting fact about RBC literature is that although we know the quantitative importance of I-S shocks as main drivers of the cycle, we are not able to exactly identify whether an I-S shock occurs. I find that capital maintenance reacts procyclically (countercyclically) following a TFP shock when the cross derivative of depreciation between utilization and maintenance is negative (positive). Also, capital maintenance reacts countercyclically following an I-S shock when the cross derivative of depreciation is positive or when the cross derivative is negative and the relative size of the substitution effect between maintenance and utilization is smaller than the marginal effect of maintenance. Arguably, the realistic case for the cross derivative is to be negative and for the relative size of the Hicksian elasticity to be smaller than the maintenance elasticity of marginal depreciation. This suggests than when a TFP shock is considered, capital maintenance reacts procyclically displaying the same behavior with the other variables. On the other hand, when an I-S shock is considered capital maintenance is the only variable that reacts countercyclically. The above result suggests that capital maintenance is the only variable that enables the identification of an I-S shock. In other terms, capital maintenance enables to distinguish an I-S shock from the other technological shocks that drive the business cycle.

The rest of the paper is organized as follows. Section 2 provides a brief survey of the existing $\mathrm{RBC}$ literature and the role of endogenous capital depreciation. Section 3 describes the economic environment and interprets the optimality conditions. Section 4 conducts a comparative statics exercise and provides the short-run effects of an I-S shock. Section 5 analytically explains the comovements and the responses of the main variables during the economic cycle and discusses the implications of the results. Finally, section 6 concludes.

\section{Some key concepts and stylized facts}

\subsection{Existing RBC literature and comovements}

The RBC literature aims to explain the macroeconomic fluctuations and the comovements of key variables, demonstrating that output, consumption, investment, and labor tend to rise and fall together during the business cycle. Two of the key technological shocks that explain a big fraction of these comovements are TFP and I-S shocks. A TFP shock is a random productivity variable that changes the relative prices of the different uses of output. TFP shocks cannot be directly measured; instead they are measured as a Solow residual by subtracting from the total output change the changes caused by the production inputs. On the other hand, I-S shocks are random changes that affect the marginal efficiency of investment and as a result change its relative price. ${ }^{2}$

\footnotetext{
${ }^{2}$ Both the TFP and I-S shocks affect the relative price of the different uses of output and investment respectively. Therefore, they cannot be considered as an "innovation" that changes the nature of the investment good.
} 
Kydland and Prescott (1982) introduce stochastic technology shocks as a key driving force of the business cycle. Long and Plosser (1983) present a similar neoclassical model, based on the idea of stochastic technology shocks as well. These two models form the foundation of RBC theory. Kydland and Prescott (1988) extend their basic framework to include varying capital utilization rate to improve their approximation of the empirical evidence. King et al. (1988), examine whether the neoclassical growth model driven by technology shocks can explain the macroeconomic fluctuations and the comovements of key variables. They show that the steady-state values of consumption, investment, output, and capital grow at an exogenous rate specified by the technology shock, whereas work effort remains constant. They also show that off the steady-state path, capital and work effort are negatively associated.

Apart from explaining the nature of macroeconomic fluctuations, the above papers attempt to capture and explain some basic cyclical features of US postwar variables, namely their volatility, comovement, and persistence. Concerning volatility, the data show that output is much more volatile than capital, hours per worker and the real wage rate. It is also more volatile than consumption of non-durables and labor productivity, approximately as volatile as total hours worked and employment, and less volatile than consumption of durables, government expenditures, and capital utilization in manufacturing. Finally, it is much less volatile than investment.

As far as the comovement of certain aggregates during the cycle is concerned, the evidence suggests that most series are procyclical. There exists a high degree of correlation between total hours worked and output, whereas no correlation exists between output, wages, government expenditures, and capital stock. Another key feature of the business cycle is the persistence of all macroeconomic variables.

Although the above models replicate several features of the data, they also pinpoint the major puzzles of RBC literature, namely the excess variability of labor hours, the resulting procyclicality of productivity, the persistence of recessions, and the large volatility of investment compared to consumption, as described in King and Rebelo (1999). Moreover, King et al. (1988) observe an overstatement of the correlation between productivity, consumption, investment, and hours worked. This has initiated further scepticism involving the so-called RBC literature puzzles, most notably productivity-hours worked puzzle involving the overstatement of the correlation between productivity and hours worked during the cycle.

A proposed solution to the above criticism is the incorporation of I-S shocks in an RBC framework. Greenwood et al. (2000) examine the short-run effects of I-S shocks on macroeconomic fluctuations in a framework including capital utilization. Using U.S. post-war data they find that technological change of this form is the source of about $30 \%$ of output fluctuations and therefore the short-run effects are relatively smaller than the long-run. They also form a two-sector (equipment and consumption sector) model to extract results for possible comovements across sectors. This analysis implies that the inputs of the sectors comove negatively, but there is no such comovement with output. Christiano and Fisher (1995) also report a positive comovement of hours worked and employment across sectors. 
Fisher (2003) includes a stochastic trend in the technology shock and assumes only one capital good. When I-S shocks are considered, permanent technology shocks account for $50 \%$ of the variation in hours worked and for $40 \%$ of the variation in output. The author also suggests that positive innovations to both neutral and I-S technological change have positive effects in labor productivity in the long-run and that these shocks are unrelated to variables such as capital taxes. Finally, Justiniano et al. (2011) distinguish I-S shocks in two types, one that changes the relative price of investment, and another that it is an exogenous disturbance to the process by which investment goods are transformed into installed capital to be used in production.

\subsection{Endogenous capital depreciation}

The capital depreciation rate varies over time depending on the pace of economic activity, meaning that depreciation is higher in good times than in recessions. Whelan (2002) highlights the importance of a non-stable depreciation rate, suggesting that a stable depreciation leads to an under-estimation of depreciation and an under-estimation of TFP growth. Boucekkine et al. (2009) present evidence from US data that suggest a non-constant depreciation rate of capital, which is sensitive to technological changes. Specifically, the authors show that the depreciation of capital has increased since 1960, accompanied by a decrease in the decline rate of the relative price of equipment and software.

The assumption of endogenous capital depreciation was first adopted by Kydland and Prescott (1988) in a standard RBC framework where the depreciation is endogenous to capital utilization. Greenwood et al. (1988) also incorporate this endogeneity assumption in a stochastic framework with I-S shocks and highlight the importance of capital utilization in mimicking the comovements in the data. Specifically, their model explains the positive comovement between investment, productivity, and consumption. In turn, Jaimovich and Rebelo (2009) highlight the importance of capital utilization in generating the comovements of the key aggregates following "news" technology shocks. In particular, they suggest that although most macroeconomic aggregates generate comovements only in response to contemporaneous shocks, when capital utilization is included in the model these comovements are a response for news (future) shocks as well.

The importance of capital maintenance is stressed by Collard and Kollintzas (2000), who construct a framework in which they distinguish between two types of labor, namely labor used on production and labor used on maintaining capital. Subsequently, they produce the low correlation between labor productivity and output shown by the stylized facts of business cycles. Licandro and Puch (2000) endogenize the depreciation rate in both capital utilization and capital maintenance in a RBC framework with TFP shocks. Their key argument is that spending on capital maintenance is a countercyclical variable that creates a propagation mechanism, which is quantitatively more important than the depreciation-in-use assumption. ${ }^{3}$ In turn, the TFP shock causes an increase in

\footnotetext{
${ }^{3}$ The depreciation-in-use assumption means that output's standard deviation is larger than that of the technology shock. Note that the countercyclicality of maintenance is an argument that is strongly criticised by recent research; see Albonico et al. (2014).
} 
output, triggered by the effects of maintenance and capital utilization. Dueker et al. (2006) state the advantages and disadvantages of endogenous and exogenous stochastic capital depreciation. Endogenous depreciation, based on maintenance and capital utilization, triggers a higher persistence on the effects of the technology shocks on output, whereas stochastic exogenous depreciation becomes an additional driving force of the cycle.

Boucekkine and Ruiz-Tamarit (2003) consider a model with capital maintenance and utilization, and conduct a comparative static analysis to examine whether capital maintenance and investment are complements or substitutes. The assumptions on the capital depreciation function play an important role in their analysis and specifically on whether the cross derivative between maintenance and utilization is positive or negative. Briefly, they suggest that the sign of this cross derivative determines the behavior of key aggregates (capital utilization, capital maintenance, depreciation rate, and investment) following a TFP shock. Boucekkine et al. (2009) develop an analytical twosector framework with capital maintenance and I-S shocks, and show that the lifetime of capital is an increasing function of neutral shocks and a decreasing one of I-S shocks. In particular, a vintage capital model is assumed, in which the I-S shock causes obsolescence of the old capital, and where a new plant is built in each period. The authors find that in such a framework the I-S causes the acceleration of the use-related depreciation and the scrapping rate. ${ }^{4}$

Boucekkine et al. (2010) find that optimal maintenance is a weighted integral of past investment and that optimal maintenance moves together with investment in the short-run as a response to a TFP shock. This essentially suggests that optimal maintenance and investment act as complementaries. Finally, Albonico et al. (2014) suggest that total output, consumption, investment, next period's capital stock, the depreciation rate, and capital maintenance rise due to a TFP shock. On the other hand, following an I-S shock all of these variables rise, apart from capital maintenance. This distinct behavior of maintenance leads the authors to suggest that capital maintenance provides a tool to spot and identify I-S shocks.

\section{The economy}

Consider a perfectly competitive closed economy, populated by a large number of identical agents. To address the issue of the effect of endogenous capital depreciation on the key macroeconomic aggregates, the model constructed builds on the basic RBC representative agent model with one sector. The representative agent owns the capital stock and allocates spending between investment and capital maintenance. Aggregate output is produced by a constant returns to scale production function

$$
y_{t}=\alpha_{t} F\left(u_{t} k_{t}, l_{t}\right)
$$

\footnotetext{
${ }^{4}$ The assumption of the two sector model allows for the I-S technological change, which leads to the creation of new plants, to be considered as an innovation. This will not be the case in the one sector model examined in this paper, as it can be seen from section 3 , but it can be relaxed in future work.
} 
where $y_{t}$ is the output of the single good in period $t, k_{t}$ is the capital stock at the beginning of period $t, u_{t}$ is the capital utilization rate and $l_{t}$ is the labor input in the same period. ${ }^{5} \alpha_{t}$ is a TFP shock formed as in Kydland and Prescott (1988) and King et al. (1988). The nonnegative constant-returns-to scale production function satisfies the usual concavity assumptions $F_{1}, F_{2}>0$, $F_{11}, F_{22}<0$ and $F_{11} F_{22}-F_{12}^{2}=0$, with $F_{12}>0$.

Capital utilization also affects the evolution of the capital stock together with spending on capital maintenance $m_{t}$ through capital depreciation. Capital accumulation therefore is described by the following equation

$$
k_{t+1}=k_{t}\left[1-\delta\left(u_{t}, \frac{m_{t}}{k_{t}}\right)\right]+i_{t}\left(1+\varepsilon_{t}\right)
$$

where $i_{t}$ is the investment in period $t$. The nonnegative depreciation rate function $\delta$ satisfies the convexity assumptions $0 \leq \delta \leq 1, \delta_{1}>0, \delta_{2}<0, \delta_{11}, \delta_{22}>0$, and $\delta_{11} \delta_{22}-\delta_{12}^{2}>0$. Hence, higher capital utilization rate results in higher depreciation, whereas a rise in maintenance has the opposite effect. The assumption that depreciation is a decreasing function of capital maintenance follows a number of studies i.e. McGrattan and Schmitz, 1999; Licandro and Puch, 2000; Collard and Kollintzas, 2000; Boucekkine and Ruiz-Tamarit, 2003; Boucekkine et al., 2009; Boucekkine et al., 2010; Albonico et al., 2014). $\delta_{12}$ is the cross derivative of the depreciation function. ${ }^{6} \varepsilon_{t}$ is an I-S shock that affects the productivity of capital goods, whereas the productivity of the existing capital is not directly affected. ${ }^{7}$ This technological disturbance is different from the usual TFP shock that affects the production function, commonly used in the RBC literature (e.g., Kydland and Prescott, 1987; King et al.,1987). $\varepsilon_{t}$ is generated by a stationary Markov distribution function $\Phi\left(\varepsilon_{t} \mid \varepsilon_{t+1}\right)$ defined on the domain $Q=[\varepsilon, \bar{\varepsilon}]$ and affects new capital on the beginning of period $t$. The introduction of capital maintenance gives a well defined investment function the derivation of which is provided in the appendix.

The representative agent derives utility from her private consumption $c_{t}$ and her time devoted to leisure. Following Greenwood et al. (1988), we assume that expected lifetime utility is given by Greenwood-Hercowitz-Huffman (GHH) preferences:

$$
E_{0}\left\{\sum_{t=0}^{\infty} \beta^{t} U\left(c_{t}-G\left(l_{t}\right)\right)\right\}
$$

The utility function satisfies the usual concavity assumptions $U^{\prime}>0, U^{\prime \prime}<0$ with $G^{\prime}>0, G^{\prime \prime}>0$ and the derivatives with respect to consumption and labor are $U_{1}>0, U_{2}<0, U_{11}, U_{22}$, $<0$,

\footnotetext{
${ }^{5}$ The variable $u_{t}$ represents the decision on the intensity of the use of capital. It is the extent to which an economic agent actually uses its productive capacity, Greenwood et al. (1988).

${ }^{6}$ Boucekkine and Ruiz-Tamarit (2003) suggest that the sign of this cross derivative shows whether the marginal efficiency of maintenance decreases or increases when the rate of capital utilisation rises. If it is positive, an increase in capital utilization results to an increase in the marginal efficiency of maintenance, expressed by the first derivative of the depreciation rate for maintenance. The economic significance of this assumption is that more intense use of capital results to more efficient maintenance for every unit of capital.

${ }^{7}$ The I-S shocks in our model are formed exactly as in Greenwood et al. (1988) and Justiniano et al. (2010). Specifically, they are an exogenous variation in the efficiency with which the final good can be transformed into physical capital and as such they cannot be considered as "innovation". This is the reason why in the capital accumulation equation the I-S shock multiplies only investment.
} 
$U_{12}<0$ and $U_{11} U_{22} U_{12}^{2}>0$. The marginal rate of substitution between consumption and labor effort depends only on $-U_{2} / U_{1}=G^{\prime}(l)$. Finally, the aggregate resource constraint is given by:

$$
y_{t}=c_{t}+i_{t}+m_{t}
$$

\subsection{The representative agent's decisions}

The representative agent maximizes her expected lifetime utility by choosing next period's capital stock $\left(k_{t+1}\right)$, labor effort $\left(l_{t}\right)$, capital utilization rate $\left(u_{t}\right)$, maintenance expenditures $\left(m_{t}\right)$, and consumption $\left(c_{t}\right)$. The model is solved by allowing only an I-S shock to drive the cycle. The solution of the model with a TFP shock is provided in the Appendix. To solve this stochastic optimization problem I use dynamic programming. Let $V\left(k_{t} ; \varepsilon_{t}\right)$ be the value function that solves the maximization problem and assume that it exists, is unique, increasing, concave, and differentiable in its first argument. The stochastic Bellman equation is described by

$$
\begin{aligned}
V\left(k_{t} ; \varepsilon_{t}\right)= & \max _{c_{t}, l_{t}, u_{t}, m_{t}, k_{t+1}}\left\{U\left(c_{t}, l_{t}\right)+\beta E_{t}\left[V\left(k_{t+1} ; \varepsilon_{t+1}\right) \mid t\right]\right\} \\
& \text { s.t. } \quad c_{t}=F\left(u_{t} k_{t}, l_{t}\right)-m_{t}-\frac{k_{t+1}}{1+\varepsilon_{t}}+\frac{k_{t}}{1+\varepsilon_{t}}(1-\delta)
\end{aligned}
$$

The first-order condition for consumption, capital utilization, labor, and capital maintenance are given by:

$$
\begin{gathered}
\frac{U^{\prime}\left(c_{t}, l_{t}\right)}{1+\varepsilon_{t}}=\beta E_{t}\left[V_{1}(t+1) \mid t\right] \\
F_{1}(t)=\frac{\delta_{1}(t)}{1+\varepsilon_{t}} \\
F_{2}(t)=G^{\prime}\left(l_{t}\right) \\
-\left(1+\varepsilon_{t}\right)=\delta_{2}(t)
\end{gathered}
$$

The envelope condition for this period's capital stock is given by:

$$
\frac{U^{\prime}\left(c_{t}, l_{t}\right)}{1+\varepsilon_{t}}=\beta E_{t}\left\{U^{\prime}\left(c_{t+1}, l_{t+1}\right)\left[F_{1} u_{t+1}+\frac{1-\delta(t+1)}{1+\varepsilon_{t+1}}+\delta_{2}(t+1) \frac{m_{t+1}}{k_{t+1}\left(1+\varepsilon_{t+1}\right)}\right] \mid t\right\}
$$

Equation (6) is the standard optimality condition regarding consumption. Equation (7) characterizes efficient capital utilization and is the usual optimality condition with respect to $u_{t}$ that describes the standard depreciation-in-use setting. The term $\delta_{1}$ represents the marginal cost in terms of increased current depreciation from utilizing capital at a higher rate, while $1 /\left(1+\varepsilon_{t}\right)$ is the current cost of replacing old with new capital. Equation (8) sets the constant marginal product of labor equal to the intertemporal consumption savings choice, which is a normalized marginal disutility of working. Equation (9) characterizes the efficient maintenance expenditure and states that the marginal benefit of maintenance on capital is equal to $-\left(1+\varepsilon_{t}\right)$, where this is the current cost of directly replacing old with new capital. 
Finally, equation (10) is the envelope condition concerning investment. The left part of this equation captures the loss in current utility, which is realized when an extra unit of investment is produced, whereas the right part captures the discounted expected future utility from the creation of this extra unit of investment. Note that a positive technology shock reduces the utility loss of an extra unit of capital. Compared to the corresponding result in Greenwood et al. (1988), equation (10) has an extra term due to the endogeneity of the depreciation rate function to capital maintenance. Since this term is negative, the existence of capital maintenance in our framework reduces the discounted expected future utility from the creation of an extra unit of investment.

Dividing both sides of equation (10) with $U^{\prime}\left(c_{t+1}, l_{t+1}\right)$, the Keynes-Ramsey rule (Euler equation) is derived:

$$
\frac{U^{\prime}\left(c_{t}, l_{t}\right)}{U^{\prime}\left(c_{t+1}, l_{t+1}\right)}=\beta E_{t}\left\{\left(1+\varepsilon_{t}\right)\left[F_{1} u_{t+1}+\frac{1-\delta}{1+\varepsilon_{t+1}}+\delta_{2} \frac{m_{t+1}}{k_{t+1}\left(1+\varepsilon_{t+1}\right)}\right] \mid t\right\}
$$

The difference with its non-stochastic analogous is the existence of the I-S shock that multiplies the second term of the equation. The rule for optimal consumption over time shows that the marginal rate of substitution between consumption in two periods depends on the discounted value of the marginal product of next period's capital stock when the effects of the depreciation, through both capital utilization and maintenance, are taken into account. It is evident that these depreciation effects depend on the I-S shock $\left(\varepsilon_{t}\right)$. Specifically, a positive I-S shock results in a higher consumption in period $t$. In contrast, a positive next period's I-S shock $\left(\varepsilon_{t+1}\right)$ results in an ambiguous effect on consumption in period $t+1$. With a positive shock in the period $t+1$ the term $(1-\delta) /\left(1+\varepsilon_{t+1}\right)$ declines, and therefore, this results in lower consumption at time $t$. On the other hand, the term $\delta_{2} m_{t+1} /\left(k_{t+1}\left(1+\varepsilon_{t+1}\right)\right)$ increases with a positive shock in period $t+1$, resulting in a higher consumption. This reflects the opposite effects of utilization and maintenance on consumption. On the one hand, a decision to utilize more capital results in an increase in this period's consumption, but on the other hand the resulting increase in the depreciation rate decreases next period's consumption. This last effect has its counterweight by the increase of next period's consumption arising from the introduction of capital maintenance.

\section{Short-run effects of I-S shocks}

\subsection{Comparative statics}

In this section, a comparative statics analysis is conducted, to capture the short-run effects of an I-S shock on investment, consumption, output, hours worked, capital utilization, capital maintenance, productivity, and output. ${ }^{8}$

\footnotetext{
${ }^{8}$ The exercise is conducted under the simplifying assumption that the disturbances are independently distributed over time so that $E_{t}\left(\varepsilon_{t+1} \mid \varepsilon_{t}\right)=E_{t}\left(\varepsilon_{t+1}\right)$. Analytical steps of the derivation of the comparative statics are provided in section A.2 of the Appendix. The analogous comparative statics for a TFP shock are presented in Table 3 and Table 4.
} 


\subsubsection{Capital utilization, labor and capital maintenance}

Totally differentiating equations (7), (8) and using (9), yields the effects of the shock on capital utilization, $u_{t}$, capital maintenance, $m_{t}$, and labor, $l_{t}$ :

$$
\begin{gathered}
\frac{d u_{t}}{d \varepsilon_{t}}=-\frac{\left(\delta_{1} \delta_{22}-\delta_{2} \delta_{12}\right)\left(F_{22}-G^{\prime \prime}\left(l_{t}\right)\right) k_{t}}{\left(1+\varepsilon_{t}\right) \Omega(t)}=-\frac{\left(F_{22}-G^{\prime \prime}\left(l_{t}\right)\right) k_{t}}{\Omega(t)} \frac{\delta_{1}}{m_{t}}\left(E M D_{m}+\epsilon_{m} H E C_{u, m}\right) \gtrless 0 \\
\frac{d l_{t}}{d \varepsilon_{t}}=\frac{F_{12} k_{t}}{\Omega(t)} \frac{\delta_{1}}{m_{t}}\left(E M D_{m}+\epsilon_{m} H E C_{u, m}\right) \gtrless 0 \\
\frac{d m_{t}}{d \varepsilon_{t}}=-\frac{k_{t}}{\delta_{22}}\left(1+\delta_{12} \frac{d u_{t}}{d \varepsilon_{t}}\right) \gtrless 0
\end{gathered}
$$

where $\Omega(t)=-\left(F_{22}-G^{\prime \prime}\left(l_{t}\right)\right)\left(\delta_{11} \delta_{22}-\delta_{12}^{2}\right)-k_{t} \delta_{22} F_{11} G^{\prime \prime}\left(l_{t}\right)\left(1+\varepsilon_{t}\right)>0$ with the positive sign arising from the concavity of $F$ and the convexity of $\delta$ and $G$. The elasticity of marginal depreciation w.r.t. $m$ is defined as $E M D_{m}=-\delta_{22} m_{t} / \delta_{2}>0 .{ }^{9}$ The Hicksian elasticity of complementaries is defined as $H E C_{u, m}=\delta \delta_{12} / \delta_{1} \delta_{2} \cdot{ }^{10}$ The elasticity w.r.t. $m$ is $\epsilon_{m}=\delta_{2} m / \delta<0$.

Equations (11)-(13) show the responses of $u_{t}, l_{t}$, and $m_{t}$ following an I-S shock in period $t$. One can see that due to the properties of $\delta$, the sign of the cross derivative $\delta_{12}$ is the same as the sign of the term $\left(E M D_{m}+\epsilon_{m} H E C_{u, m}\right)$. The latter captures the reactions due to the intertemporal substitution of $m\left(E M D_{m}\right)$ and due to a change of the price of maintaining capital and utilizing capital $\left(\epsilon_{m} H E C_{u, m}\right)$. From equations (11)-(13) it is evident that $u$ and $l$ always commove, a finding that is verified from the data and also exists in Greenwood et al. (1988). This term shows that the intertemporal effect of a maintenance change due to an I-S shock is reduced by the intratemporal effect of a maintenance change $\left(\epsilon_{m} H E C_{u, m}\right)$ that results from the substitution of maintenance with utilization.

The sign of the cross derivative $\delta_{12}$ affects the sign of the comparative statics through the elasticity of complementaries $H E C_{u, m}$. This result reinforces the result of Boucekkine and RuizTamarit (2003); however, here the responses are affected by the interplay between $E M D_{m}$ and $\epsilon_{m} H E C_{u, m}$. Finally, the response of capital maintenance, shown in equation (13), changes based on the relative response of capital utilization. Specifically, the interplay between the cross derivative $\delta_{12}$ and the response of utilization $\frac{d u_{t}}{d \varepsilon_{t}}$ determines the sign of the response of maintenance.

\footnotetext{
${ }^{9}$ The elasticity of marginal depreciation is the inverse of the elasticity of intertemporal substitution of $m$, and measures the speed of adjustment to the steady state.

${ }^{10}$ The general definition of this elasticity is the responsiveness in the quantity demanded of one good when a change on the price of the other good occurs. Here, it is equal to the cross quantity elasticity of the depreciation rate function and its sign depends on the sign of $\delta_{12}$. It shows the complementarity or substitubility of $u$ and $m$.
} 


\subsubsection{Marginal productivity of labor}

Totally differentiating the marginal productivity of labor, $F_{2}\left(u_{t} k_{t}, l_{t}\right)$ and substituting equations (11), (12), given that $k_{t}$ is predetermined, gives the response of the marginal product of labor:

$$
\frac{d F_{2}(t)}{d \varepsilon_{t}}=\overbrace{\frac{G^{\prime \prime}(t) F_{12} k_{t}}{\Omega(t)} \frac{\delta_{1}}{m_{t}}}^{(+)}\left(E M D_{m}+\epsilon_{m} H E C_{u, m}\right) \gtrless 0
$$

Again, this response is affected by $\delta_{12}$ and $\epsilon_{m} H E C_{u, m}$, through a mechanism where changes in capital maintenance affect capital utilization and therefore total output.

\subsubsection{Consumption and next period's capital stock}

Totally differentiating equations (5) and (6) and substituting equations (11)-(13) gives the impact effects of the I-S shock $\varepsilon_{t}$, on consumption and next period's capital stock:

$$
\begin{aligned}
& \frac{d c_{t}}{d \varepsilon_{t}}= \overbrace{i_{t} \frac{\beta\left(1+\varepsilon_{t}\right) E_{t}\left(V_{k k}(t+1) \mid t\right)}{U^{\prime \prime}+\beta E_{t}\left(V_{k k}(t+1) \mid t\right)\left(1+\varepsilon_{t}\right)^{2}}}^{(+)}+\overbrace{\frac{U^{\prime} /\left(1+\varepsilon_{t}\right)}{U^{\prime \prime}+\beta E_{t}\left(V_{k k}(t+1) \mid t\right)\left(1+\varepsilon_{t}\right)^{2}}}^{(-)} \\
& \frac{\overbrace{+\frac{F_{2} F_{12} k_{t}}{\Omega(t)} \frac{\delta_{1}}{m_{t}}}^{(+)}\left(E M D_{m}+\epsilon_{m} H E C_{u, m}\right) \lessgtr 0}{d k_{t+1}}=\overbrace{i_{t} \frac{(-)}{U^{\prime \prime}+\beta E_{t}\left(V_{k k}(t+1) \mid t\right)\left(1+\varepsilon_{t}\right)^{2}}}^{(+)}-\overbrace{\frac{U^{\prime \prime}}{U^{\prime \prime}+\beta E_{t}\left(V_{k k}(t+1) \mid t\right)\left(1+\varepsilon_{t}\right)^{2}}>0^{11}}^{(-)}
\end{aligned}
$$

In order to understand the above effects of the I-S shock each term is going to be examined separately. The first term of equation (15), $\left[i_{t} \beta\left(1+\varepsilon_{t}\right) \int V_{k k} d \Phi\right] /\left[U^{\prime \prime}+\beta \int V_{k k} d \Phi\left(1+\varepsilon_{t}\right)^{2}\right]$, illustrates a positive income effect following a technological change, which positively affects current consumption. The second term, $\left[U^{\prime} /\left(1+\varepsilon_{t}\right)\right] /\left[U^{\prime \prime}+\beta \int V_{k k} d \Phi\left(1+\varepsilon_{t}\right)^{2}\right]$, demonstrates a negative intertemporal substitution effect that explains the tendency for current consumption to fall due to an improvement on the efficiency of capital caused by the I-S shock. ${ }^{12}$ The third term of equation (15), $\left(F_{2} F_{12} k_{t} / \Omega(t)\right)\left(\delta_{1} / m_{t}\right)\left(E M D_{m}+\epsilon_{m} H E C_{u, m}\right)$, includes a new element introduced by this model, $E M D_{m}+\epsilon_{m} H E C_{u, m}$. This term represents the intratemporal margin of substitution effect between next period's capital stock $k_{t+1}$ and consumption $c_{t}$, and is affected by the intertemporal substitution of capital maintenance $m_{t}\left(E M D_{m}\right)$ and the intratemporal substitution effect $\left(\epsilon_{m} H E C_{u, m}\right)$. Again the response of current consumption on an I-S shock depends on the complementarity or substitutability of the variables $m_{t}$ and $u_{t}$ as expressed by the elasticity $H E C_{u, m}$.

\footnotetext{
${ }^{11}$ Note that these formulas presume that $V(t+1)$ is a twice differentiable concave function in $k$ (Sargent, 1980).

${ }^{12}$ Greenwood et al. (1988) state that: "The standard macroeconomic presumption is that the intertemporal substitution effect generated by such technological shift will dominate the income effect, a situtation ensured if the initial level of investment is small enough."
} 
Following Greenwood et al. (1988) and since the assumption $F_{12}>0$ holds, an increase in capital utilization raises the marginal productivity of labor $\left(F_{2}\right)$ and therefore produces a substitution from leisure towards consumption, depending on the degree of substitutability between capital utilization and capital maintenance.

Concerning the response of next period's capital stock expressed by equation (16), it can be noted that it is always positive, in line with Greenwood et al. (1988). The first term of the equation, $i_{t} U^{\prime \prime} /\left[U^{\prime \prime}+\beta \int V_{k k} d \Phi\left(1+\varepsilon_{t}\right)^{2}\right]$, is the positive income effect that shows how a given level of $k_{t+1}$ can now be obtained with a lower lever of current investment as a result of the I-S shock. The second term, $-U^{\prime} /\left[U^{\prime \prime}+\beta \int V_{k k} d \Phi\left(1+\varepsilon_{t}\right)^{2}\right]$, is a positive substitution effect implying that a technology shock forces the household to increase next period's capital stock as there is an increase of the productivity of newly produced capital. ${ }^{13}$

\subsubsection{Investment, capital depreciation, and output}

The effect on gross investment can be found by totally differentiating the capital accumulation equation (2) and dividing with the shock:

$$
\frac{d i_{t}}{d \varepsilon_{t}}=\frac{1}{\left(1+\varepsilon_{t}\right)}\left[\frac{d k_{t+1}}{d \varepsilon_{t}}-i_{t}+\delta_{1} \frac{d u_{t}}{d \varepsilon_{t}}+\frac{\delta_{2}}{k_{t}} \frac{d m_{t}}{d \varepsilon_{t}}\right] \gtrless 0
$$

The first term, $\frac{d k_{t+1}}{d \varepsilon_{t}}$, illustrates a type of positive substitution effect and the second term, $-i_{t}$, represents a negative type of income effect. ${ }^{14}$ The last two terms, $\delta_{1} \frac{d u_{t}}{d \varepsilon_{t}}$ and $\frac{\delta_{2}}{k_{t}} \frac{d m_{t}}{d \varepsilon_{t}}$, have an ambiguous effect on gross investment depending on the sign of $\delta_{12}$ and $E M D_{m}+\epsilon_{m} H E C_{u, m}$.

Finally, by totally differentiating the production function, gives the effects of the shock on total output:

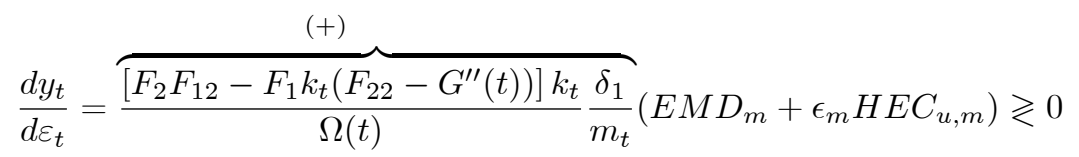

Again the sign of $\left(E M D_{m}+\epsilon_{m} H E C_{u, m}\right)$ is ambiguous and therefore the procyclicality or countercyclicality of the variables is ambiguous as well. Equation (18) shows that total output always comoves with capital utilization and the employment rate.

To conclude, the sign of the cross derivative $\delta_{12}$, together with the interplay between the elasticity of marginal depreciation w.r.t maintenance, the elasticity of maintenance, and the Hicksian elasticity of complementaries determine the responses of utilization, labor and maintenance, productivity of labor, consumption, investment, capital depreciation, and output following an I-S shock.

\footnotetext{
${ }^{13}$ Note that the first-order conditions (7)-(9), imply that the variables $u_{t}, l_{t}$, and $m_{t}$ depend, respectively, only on the current shock $\varepsilon_{t}$ and not on its future values. Therefore, whether $\varepsilon_{t}$ is serially correlated over time does not affect the current values of these variables. On the other hand, this in not the case for $k_{t+1}$, since equation (6) holds only for period $t$ and therefore under a serially correlated assumption for the shock $\varepsilon_{t}, \frac{d k_{t+1}}{d \varepsilon_{t}}$ cannot be unambiguously signed.

${ }^{14}$ Greenwood et al. (1988) state that: "If the initial investment is relatively small, the substitution effect will clearly dominate".
} 
Tables 3 and 4 present the equivalent comparative statics for a TFP. Note that under a TFP shock, all variables react procyclically apart from maintenance, the response of which depends only on the sign of the cross derivative $\delta_{12}$. Specifically, when $\delta_{12}<0$ maintenance is procyclical, whereas it becomes countercyclical when $\delta_{12}>0$. In line with this result, Albonico et al. (2014) empirically show that capital maintenance reacts procyclical following a TFP shock which can be interpreted as $\delta_{12}<0$.

Finally, the dynamic effects of an I-S shock and the persistence of these effects are computed and are presented in the Appendix. The results are the standard results suggested by the literature (see Greenwood et al. 1988) and all the variables demonstrate persistent effects. In contrast with the short-run effects, the only variable affected by the cross derivative is capital maintenance.

\subsection{Explanation of the comparative statics}

In order to explain the above comparative statics, the analysis is focused on the cross derivative $\delta_{12}$, specifically by taking cases for the sign of the expression $E M D_{m}+\epsilon_{m} H E C_{u, m}$ together with the relative size of the substitution and income effects in each case.

\subsection{1 $\delta_{12} \geqslant 0$}

When the cross derivative is positive then $H E C_{u, m}<0$ and $E M D_{m}+\epsilon_{m} H E C_{u, m}>0$. This case gives that $\frac{d u_{t}}{d \varepsilon_{t}}>0, \frac{d l_{t}}{d \varepsilon_{t}}>0, \frac{d m_{t}}{d \varepsilon_{t}}<0, \frac{d F_{2 t}}{d \varepsilon_{t}}>0, \frac{d c_{t}}{d \varepsilon_{t}} \gtrless 0, \frac{d i_{t}}{d \varepsilon_{t}} \gtrless 0, \frac{d \delta_{t}}{d \varepsilon_{t}}>0, \frac{d y_{t}}{d \varepsilon_{t}}>0$.

Result 1. If the cross derivative $\delta_{12} \geqslant 0$, then utilization $\left(u_{t}\right)$, labor $\left(l_{t}\right)$, labor productivity $\left(F_{2, t}\right)$, and capital depreciation $\left(\delta_{t}\right)$ react procyclically with output $\left(y_{t}\right)$ following an I-S shock. Maintenance $\left(m_{t}\right)$ reacts countercyclically.

This result is in line with Greenwood et al. (1988) and Albonico et al. (2014) and means that the I-S shock reduces the marginal cost of capital utilization and therefore induces a higher $u_{t}$. Also, the positive response of labor implies that the I-S shock reduces the cost of labor. Hence it induces a higher $l_{t}$, and since $F_{12}>0$, labor productivity also increases $\left(\frac{d F_{2 t}}{d \varepsilon_{t}}>0\right)$. The negative response of capital maintenance $\left(m_{t}\right)$ means that the I-S shock increases the relative cost of maintaining existing capital and therefore capital maintenance is reduced. The interesting finding is that under the case of $\delta_{12}>0$ and when a TFP shock is considered maintenance again reacts countercyclically. This comes in contrast with the findings of Albonico et al. (2014) who suggest that maintenance reacts countercyclically only following an I-S shock.

The sign of the response of consumption $\left(c_{t}\right)$ is determined by whether the positive income effect together with the positive intratemporal substitution effect are larger or smaller than the negative intertemporal substitution effect (see equation 15). On the other hand, the new element described by the term $\left(F_{2} F_{12} k_{t} / \Omega(t)\right)\left(\delta_{1} / m_{t}\right)\left(E M D_{m}+\epsilon_{m} H E C_{u, m}\right)$ of equation (15), which under the case examined $\left(\delta_{12} \geqslant 0\right)$ is positive, reinforces the result of Greenwood et al. (1988), and our model provides a stronger channel through which consumption can react procyclically.

Finally, the response of investment $\left(i_{t}\right)$ is also determined by the relative size of income and 
substitution effects together with the positive depreciation rate effect coming from the term $\delta_{1} \frac{d u_{t}}{d \varepsilon_{t}}+$ $\frac{\delta_{2}}{k_{t}} \frac{d m_{t}}{d \varepsilon_{t}}$ (due to the assumption that $\delta_{12} \geqslant 0$ ). Again, this analysis provides a stronger channel within which consumption and investment can react procyclically.

\subsection{2 $\delta_{12}<0$}

When the cross derivative is negative we get that $H E C_{u, m}>0$ and the sign of the expression $E M D_{m}+\epsilon_{m} H E C_{u, m}$ depends on whether the intratemporal substitution effect between maintenance and capital utilization, $\epsilon_{m} H E C_{u, m}$ is larger or smaller, in absolute terms, than the positive intertemporal substitution effect of maintenance expressed by the elasticity $E M D_{m}$.

- If $\left|\epsilon_{m} H E C_{u, m}\right|>E M D_{m}$ then $\frac{d u_{t}}{d \varepsilon_{t}}<0, \frac{d l_{t}}{d \varepsilon_{t}}<0, \frac{d m_{t}}{d \varepsilon_{t}}<0, \frac{d F_{2 t}}{d \varepsilon_{t}}<0, \frac{d c_{t}}{d \varepsilon_{t}} \gtrless 0, \frac{d i_{t}}{d \varepsilon_{t}} \gtrless 0, \frac{d \delta_{t}}{d \varepsilon_{t}} \gtrless$ $0, \frac{d y_{t}}{d \varepsilon_{t}}<0$.

Result 2. Under the assumption that $\left|\epsilon_{m} H E C_{u, m}\right|>E M D_{m}$ and as long as $\delta_{12}<0$, then utilization $\left(u_{t}\right)$, labor $\left(l_{t}\right)$, maintenance $\left(m_{t}\right)$, labor productivity $\left(F_{2 t}\right)$, and output $\left(y_{t}\right)$ respond negatively following an I-S shock. The response of capital depreciation depends on the relative size of the capital utilization effect compared to the capital maintenance effect.

The response of next period's capital stock is always positive and now reacts countercyclically with output, implying a different finding from Greenwood et al. (1988) and Albonico et al. (2014). ${ }^{15}$ This essentially means that the I-S shock increases the marginal cost of capital utilization and therefore $u_{t}$ is more expensive in relative terms. It also increases the cost of labor, and hence it induces a lower $l_{t}$, and reduces the productivity of labor $\left(\frac{d F_{2 t}}{d \varepsilon_{t}}<0\right)$. The negative response of capital maintenance $\left(m_{t}\right)$ means that the I-S shock increases the relative cost of maintaining existing capital and therefore capital maintenance is reduced.

Under the case $\delta_{12}<0$ and $\left|\epsilon_{m} H E C_{u, m}\right|>E M D_{m}$, the response of the depreciation rate $\frac{d \delta_{t}}{d \varepsilon_{t}}$ is positive if the effect of capital maintenance $\left(\frac{\delta_{2}}{k_{t}} \frac{d m_{t}}{d \varepsilon_{t}}\right)$ is larger than the effect of capital utilization $\left(\delta_{1} \frac{d u_{t}}{d \varepsilon_{t}}\right)$, and negative under the opposite case (see Table 1$)$.

Again, the response of consumption $\left(c_{t}\right)$ is determined by whether the positive income effect together with the positive intratemporal substitution effect are larger or smaller than the negative intertemporal substitution effect and the new term which now becomes negative (i.e. $\left(F_{2} F_{12} k_{t} / \Omega(t)\right)\left(\delta_{1} / m_{t}\right)\left(E M D_{m}+\epsilon_{m} H E C_{u, m}\right)$, see equation (15)). A similar outcome is implied for the response of investment as well, because now the term $\delta_{1} \frac{d u_{t}}{d \varepsilon_{t}}$ is negative.

- If $\left|\epsilon_{m} H E C_{u, m}\right|<E M D_{m}$ then $\frac{d u_{t}}{d \varepsilon_{t}}>0, \frac{d l_{t}}{d \varepsilon_{t}}>0, \frac{d m_{t}}{d \varepsilon_{t}} \gtrless 0, \frac{d F_{2 t}}{d \varepsilon_{t}}>0, \frac{d c_{t}}{d \varepsilon_{t}} \gtrless 0, \frac{d i_{t}}{d \varepsilon_{t}} \gtrless 0, \frac{d \delta_{t}}{d \varepsilon_{t}} \gtrless$ $0, \frac{d y_{t}}{d \varepsilon_{t}}>0$, which is almost the same as in the case $\delta_{12} \geqslant 0$.

Note that in this case the response of capital maintenance is positive (negative) when $\delta_{12} \frac{d u_{t}}{d \varepsilon_{t}}>1$ $(<1)$ (see equation 13). Also, the response of the depreciation rate is positive if $\delta_{12} \frac{d u_{t}}{d \varepsilon_{t}}<1$. It should be noted that no straightforward results can be derived for the case of a negative cross

\footnotetext{
${ }^{15}$ Therefore this case is more of an analytical exercise rather than showing the real effects shown by the data.
} 
derivative $\delta_{12}$. Several subcases for the relative size of the substitution and income effects, and also for the relative effects of capital maintenance and capital utilization need to be compared. McGrattan and Schmitz (1999) use Canadian data to estimate the series for maintenance and observe that it has a positive correlation with output. Also, Albonico et al. (2014) estimate the series for depreciation and capital maintenance for US and Canada and find that both variables comove with output. The mixed results of this paper reinforce the findings of Albonico et al. (2014) who find that maintenance reacts procyclically following a TFP shock, which in this model means that $\delta_{12}<0$. The latter together with the fact that under the case $\left|\epsilon_{m} H E C_{u, m}\right|<E M D_{m}$ and $\delta_{12} \frac{d u_{t}}{d \varepsilon_{t}}<1$ capital depreciation reacts procyclically following an I-S shock, as suggested by the empirical evidence, and maintenance reacts countercyclically means that maintenance provides a tool to distinguish an I-S shock from the other technology shocks that may drive the cycle. This case is the most important one, as it is able to explain the empirical facts for capital depreciation. In particular, although we do not have a reason to assume whether the cross derivative $\delta_{12}$ is positive or negative, the above case suggests that in order to capture the comovements suggested by the stylized facts, then $\delta_{12}$ should be negative, and also $\left|\epsilon_{m} H E C_{u, m}\right|<E M D_{m}$ with $\delta_{12} \frac{d u_{t}}{d \varepsilon_{t}}<1$.

Result 3. Under the assumption that $\left|\epsilon_{m} H E C_{u, m}\right|<E M D_{m}$ and as long as $\delta_{12}<0$, then utilization $\left(u_{t}\right)$, labor $\left(l_{t}\right)$, and labor productivity $\left(F_{2 t}\right)$ react procyclically following an $I$-S shock. The sign of the response of maintenance $\left(m_{t}\right)$ depends on whether $\delta_{12} \frac{d u_{t}}{d \varepsilon_{t}} \gtrless 1$. The response of the capital depreciation rate depends on the relative size of the effect of capital utilization compared to that of capital maintenance.

Result 4. Maintenance $\left(m_{t}\right)$ reacts procyclically with output following an $I-S$ shock, only when $\delta_{12}<0$ and $\left|\epsilon_{m} H E C_{u, m}\right|>E M D_{m}$ or $\left|\epsilon_{m} H E C_{u, m}\right|<E M D_{m}$ with $\delta_{12} \frac{d u_{t}}{d \varepsilon_{t}}>1$.

Result 4 implies that capital maintenance is important to identify an I-S shock. In particular if we combine it with the fact that the empirical implications suggest that $\delta_{12}<0,\left|\epsilon_{m} H E C_{u, m}\right|<$ $E M D_{m}$, and $\delta_{12} \frac{d u_{t}}{d \varepsilon_{t}}<1$, then following a TFP shock, capital maintenance reacts procyclically (see Table 3) whereas following an I-S shock, capital maintenance reacts countercyclically. Thus capital maintenance is the only variable that enables to "spot" and identify an I-S shock. The short-run effects are analytically shown in Table $1 .^{16}$

\section{Implications of the model: Comovements and volatility}

Allowing for the depreciation-in-use hypothesis, implies that the depreciation rate is higher in good times, and as such, capital utilization follows a similar behavior. This model, generates the comovements shown by the data apart from the behavior of maintenance. Specifically, under all cases for the cross derivative $\delta_{12}$, capital utilization, labor productivity, labor, and output always comove. Also, there exists a stronger channel compared to Greenwood et al. (1988), which works through the complementarity/substitutability of maintenance with utilization that allows consumption and investment to comove.

\footnotetext{
${ }^{16}$ The special case where $\delta_{12}<0$ and $\epsilon_{m} H E C_{u, m}=E M D_{m}$ is provided in the Appendix.
} 
The procyclical or countercyclical reaction of maintenance following a technology shock has to do 1) with the assumptions for the depreciation rate function, and 2) with the nature of the shock itself. Under the case $\delta_{12} \geqslant 0$ and $\delta_{12}<0$ with $\left|\epsilon_{m} H E C_{u, m}\right|<E M D_{m}$, all variables react procyclically following an I-S shock apart from capital maintenance, which reacts countercyclically. ${ }^{17}$ The empirical evidence of McGrattan and Schmitz (1999) and Albonico et al. (2014) suggest that capital maintenance, labor, capital utilization, and capital depreciation are procyclical. When this evidence is combined with the results of the paper, it enables to find under which assumption for the capital depreciation function (i.e., for the cross derivative and the relative sizes) the model replicates the above stylized facts. In particular, as total output should always rise after a technology shock, the case of $\delta_{12}<0$ with $\left|\epsilon_{m} H E C_{u, m}\right|>E M D_{m}$ is not a realistic one. Moreover, note that all the variables react procyclically following a TFP shock (see Table 3) when the sign of the cross derivative is negative.

From the above, I conclude that the realistic assumptions for the capital depreciation are given by the case $\delta_{12}<0$ with $\left|\epsilon_{m} H E C_{u, m}\right|<E M D_{m}$. Therefore, the results suggest that capital maintenance reacts procyclically in the short run following a TFP shock and countercyclically following an I-S shock. This does not mean that overall capital maintenance is a countercyclical variable or that TFP shocks are more important than I-S shocks, as other shocks may drive the cycle which cause a procyclical behavior of capital maintenance. The actual implication is that all the variables, apart from capital maintenance, react procyclically following an I-S shock. Capital maintenance reacts procyclically following a TFP shock, which suggests that the incorporation of capital maintenance enables distinguishing and identifying an I-S shock from the other technological shocks that affect an economy.

Another aspect of the model is that it allows reproducing the low correlation between labor productivity and growth over the business cycle. In particular, when comparing labor productivity and output (equations (14) and (18)), we can express the response of output as a function of the response of the labor productivity (i.e., $\left.\frac{d y_{t}}{d \varepsilon_{t}}=\frac{d F_{2}}{d \varepsilon_{t}}\left(1 / G^{\prime \prime} F_{12}\right)\left[F_{2} F_{12}-F_{1} k_{t}\left(F_{22}-G^{\prime \prime}\right)\right]\right)$. From the concavity assumption for the production and utility functions we find that this correlation is positive. The interesting fact is that the common part (i.e., $\left.\left(k_{t} \delta_{t} / \Omega(t) m_{t}\right)\left(\epsilon_{m} H E C_{u, m}+E M D_{m}\right)\right)$ of the responses of output and labor productivity affects the size of this correlation. In particular, the sign of $\delta_{12}$, together with the relative effect of the expression $\epsilon_{m} H E C_{u, m}+E M D_{m}$, seems to play a crucial role in reducing the size of the correlation between output and labor productivity.

The same model yields more straightforward results for a TFP shock. Utilization, labor, labor productivity, and consumption react procyclically with output. ${ }^{18}$ The effect on maintenance once again depends on $\delta_{12}$ but only concerning its sign. If $\delta_{12}>0$ then maintenance reacts countercyclically with output and if $\delta_{12}<0$ it reacts procyclically. This reinforces and extends the result of Albonico et al. (2014). Specifically, it is not capital maintenance that helps recognizing

\footnotetext{
${ }^{17}$ All these comovements and responses can be seen in Tables 1-4.

${ }^{18}$ The comparative statics of such an exercise are analytically presented in Table 3 , where there are presented the short-run effects of three models with TFP shocks, one with capital utilization only, one with capital maintenance only, and one with both.
} 
and identifying an I-S shock, but the cross derivative $\delta_{12}$ and the relative size of the expression $\epsilon_{m} H E C_{u, m}+E M D_{m}$.

It is important to note that the qualitative importance of capital maintenance is similar to that of capital utilization, which extents the finding by Greenwood et al. (1988) and Jaimovich and Rebelo (2009), who highlight the importance of capital utilization in generating the comovements shown in the data. As shown in Table 2, when only an I-S shock is considered, capital maintenance by itself does not give a result for labor, labor productivity, and output. On the other hand, when only a TFP shock is considered (Table 3) maintenance generates the comovements of the key aggregates suggested by the stylized facts of the business cycle. For example, in the second column of Table 3 , labor, investment and output always comove. From the short-run effect for consumption once again it can be seen that there is a positive income effect (i.e. $\left.F \beta E_{t}\left[V_{11} \mid t\right] /\left\{U^{\prime \prime}+\beta E_{t}\left[V_{11} \mid t\right]\right\}\right)$ and a negative intertemporal substitution effect (i.e. $\left.U^{\prime \prime} F_{2} G^{\prime} /\left[\left(\alpha_{t} F_{22}-G^{\prime \prime}\right)\left(U^{\prime \prime}+\beta E_{t}\left[V_{11} \mid t\right]\right)\right]\right)$. Hence, the model provides a channel through which both consumption and investment can react procyclically with output. Also, the introduction of both maintenance and utilization in a model with TFP shocks gives us straightforward results on consumption (see third columns of Tables 3 and 4). All the comparative static results for a model with I-S or TFP shocks and with or without capital maintenance and capital utilization are analytically presented in Tables 1-3. Table 4, gives the effects of both a TFP shock and an I-S shock on al variables.

In terms of output volatility, King and Rebelo (1999) highlight that the relatively large size of the Solow residual is the Achilles' heal of the RBC models. ${ }^{19}$ The introduction of capital maintenance and the sign of the cross derivative $\delta_{12}$, together with the relative effect of the expression $\epsilon_{m} H E C_{u, m}+E M D_{m}$, provide a channel through which the Solow residuals necessary to match the output variation in the data are reduced. Taking the total derivative of the production function (1) with respect to time $t$ and solving for the Solow residual yields $S R_{t}=$ $\left[\frac{\partial y_{t}}{\partial t}-\left(F_{1}\left(k_{t} \frac{\partial u_{t}}{\partial t}+u_{t} \frac{\partial k_{t}}{\partial t}\right)+F_{2} \frac{\partial l_{t}}{\partial t}\right)\right] / y_{t}$. Following an I-S shock, which results to a change in the relative price of investment, the firm changes the decision for capital maintenance and capital utilization. This decision passes through the channel of the relative size $\epsilon_{m} H E C_{u, m}+E M D_{m}$, which in turn changes the size of the residuals (see also Collard and Kollintzas, 2000).

In general, the incorporation of maintenance in the model alters the standard effects of Greenwood et al. (1988) in terms of volatility. The first column of Table 2 reports the results of Greenwood et al. (1988) and the third column the results of our model with capital maintenance. Evidently, the ambiguous term $\epsilon_{m} H E C_{u, m}+E M D_{m}$ changes the size of the response, resulting in a different volatility of the main aggregates throughout the cycle.

\footnotetext{
${ }^{19}$ The Solow residual is the part of growth that cannot be explained through increased capital or labor. Solow residuals measure total factor productivity.
} 


\section{Conclusions}

This paper extends the study of Greenwood et al. (1988; 2000) and Boucekkine and Ruiz-Tamarit (2003) in a model with an I-S shock in which capital depreciation is endogenous to capital maintenance and capital utilization. An analytical comparative statics exercise is performed that yields several results concerning the comovements and the procyclicality/countercyclicality of our key variables and their volatilities.

Specifically, this paper provides an analysis of the dynamic effects following technological shocks when capital maintenance endogenously affects the depreciation rate. First, the model builds on the classic model of Greenwood et al. (1988) with an I-S shock by assuming that the depreciation rate is endogenous on capital maintenance and derives the short-run effects of an I-S and a TFP shock. In addition to the crucial role played by the cross derivative, as suggested by Boucekkine and Ruiz-Tamarit (2003), the relative size of the elasticities concerning the depreciation rate is also important. As there is no a priori reason to believe that the cross derivative and the relative size of the elasticities are negative or positive, such an explicit analysis is necessary to understand the dynamics driving the cycle.

Second, the results following I-S shocks are compared to those following TFP shocks. When the cross derivative of the depreciation between utilization and maintenance is negative, and the relative size of the complementarity of maintenance and utilization with the intertemporal substitution of maintenance is positive, capital maintenance reacts countercyclically following an I-S shock and procyclically following a TFP shock. This case matches the pattern observed in Canadian data (Albonico et al, 2014) and enables to distinguish and identify an I-S shock.

Third, the analysis shows that capital maintenance provides a tool to reduce the Solow residuals assumed by standard RBC models so as to match the output volatility suggested by the data. This finding opens up pathways for future work. In particular, introducing labor-intensive capital maintenance might lead to a model that not only explains the comovements of the key aggregates better but also requires less volatile technology shocks to explain output volatility. Such a finding may arise from the reallocation of labor between production and maintenance activities that might result to a reduction in the Solow residuals.

Finally, given the importance of technological innovation, further research might be needed to better understand the factors that affect the business cycle. This paper assumes that there is only one capital good and therefore spending on capital maintenance is employed to preserve this capital good. Extending the model of this paper to a two-sector vintage capital model with endogenous capital depreciation would allow to consider "new capital" as "innovation". Given the increasing impact of new technologies on the firm decisions, further work on their effects on the business cycle would be useful for extending the analysis of this paper.

\section{References}

-Albonico A., Kalyvitis S., Pappa E., 2014. "Capital Maintenance and Depreciation over the Business Cycle". Journal of Economic Dynamics and Control 39, 273-286. 
-Ambler, S., Paquet, A., 1994. "Stochastic depreciation and the business cycle". International Economic Review 35, 101-116.

-Barro R.J., King R.G., 1984. "Time-Seperable Preferences and Intertemporal-Substitution Models of Business Cycles". Quarterly Journal of Economics 99 (4), 817-839.

-Bils M.J., Cho J. O., 1994. "Cyclical factor utilization". Journal of Monetary Economics 33 (2), 319-354.

-Bitros G., 1976. "A Statistical Theory of Expenditures in Capital Maintenance and Repair". Journal of Political Economy 84 (5), 917-936.

-Burnside C., Eichenbaum M., 1996. "Factor-hoarding and the propagation of business-cycle shocks". American Economic Review 86 (5), 1154-74.

-Boucekkine R., Ruiz-Tamarit R., 2003. "Capital Maintenance and Investment: Complements or Substitutes?". Journal of Economics 78 (1), 1-28.

-Boucekkine R., Del Rio F., Martinez B., 2009. "Technological Progress, Obsolescence, and Depreciation". Oxford Economic Papers 61, 440-466.

-Boucekkine R., Fabbri G., Gozzi F., 2010. "Capital Maintenance and Investment: Complements or Substitutes? A Reappraisal". Journal of Economic Dynamics and Control 34 (12), 2420-2439.

-Christiano L., Fisher J., 1995. "Tobin's Q and Asset Returns: Implications for Business Cycle Analysis. Working Paper Series, Macroeconomic Issues Federal Reserve Bank of Chicago 95-14.

-Collard F, Kollintzas T., 2000. "Maintenance, Utilization, and Depreciation along the Business Cycle". CEPR Discussion Papers, 2477.

-Dueker M., Fischer A., Dittmar R., 2002. "Stochastic Capital Depreciation and the Comovement of Hours and Productivity". The B.E. Journal of Macroeconomics 6(3), ISSN (online) 15345998.

-Fisher J., 2003. "Technology Shocks and the Business Cycle". Chicago Fed Letter, issue Mar.

-Furlanetto F., Seneca M., 2014. "New Perspectives on Depreciation Shocks as a Source of Business Cycle Fluctuations". Macroeconomic Dynamics 18 (6), 1209-1233.

-Greenwood J., Hercowitz Z., Huffman G W., 1988. "Investment, Capacity Utilization, and the Real Business Cycle". American Economic Review 78 (3), 402-17.

-Greenwood J., Hercowitz Z., Krusell P., 2000. "The role of investment-specific technological change in the business cycle". European Economic Review 44 (1), 91-115.

-Ireland P. N., 2013. "Stochastic Growth in the United States and Euro Area". Journal of the European Economic Association 11 (1), 1-24, 02.

-Jaimovich N., Rebelo S., 2009. "Can News About the Future Drive the Business Cycle?" American Economic Review 99 (4), 1097-1118.

-Justiniano A., Primiceri G. E., Tambalotti A., 2010. "Investment shocks and business cycles". Journal of Monetary Economics 57 (2), 132-145.

-Justiniano A., Primiceri G. E., Tambalotti A., 2011. "Investment shocks and the relative price of investment". Review of Economic Dynamics 14 (1), 102-121. 
-King R. G., Rebelo S., 1999. "Resuscitating Real Business Cycles". Handbook of Macroeconomics 1, part B, 927-1007.

-King R. G., Plosser C, Rebelo S., 1988. "Production Growth and Business Cycles: I. The Basic Neoclassical Model". Journal of Monetary Economics 21, 2-3, 195-232.

-Kydland F. E., Prescott E.C., 1982. "Time to Build and Aggregate Fluctuations". Econometrica, 50 (6), 1345-1370.

-Kydland F. E., Prescott E.C., 1988. "The workweek of Capital and its Cyclical Implications". Journal of Monetary Economics 21 (2-3), 343-360.

-Licandro O., Puch L.A., 2000. "Capital Utilization, Maintenance Costs and the Business Cycle". Annales d' Economie et de Statistique 58, 143-164.

-Long J., Plosser C., 1983. "Real Business Cycle". Journal of Political Economy 91 (1), 36-69.

-Lucas R., 1983. "Capacity, Overtime, and Empirical Production Functions". American Economic Review 60 (2), 23-27.

-McGrattan E R., Schmitz, J. A., 1999. "Maintenance and repair: too big to ignore," Quarterly Review, Federal Reserve Bank of Minneapolis 23 (4), 2-13.

-Mukoyama T., 2008. "Endogenous Depreciation, Mismeasurement of Aggregate Capital, and the Productivity Slowdown". Journal of Macroeconomics 30 (1), 513-522.

-Sargent T., 1980. "Tobin's q and the Rate of Investment in General Equilibrium". CarnegieRochester Conference Series on Public Policy 12 (1), 107-154.

-Whelan K., 2002. "Computers, Obsolescence, and Productivity". The Review of Economics and Statistics 84 (3), 445-461. 


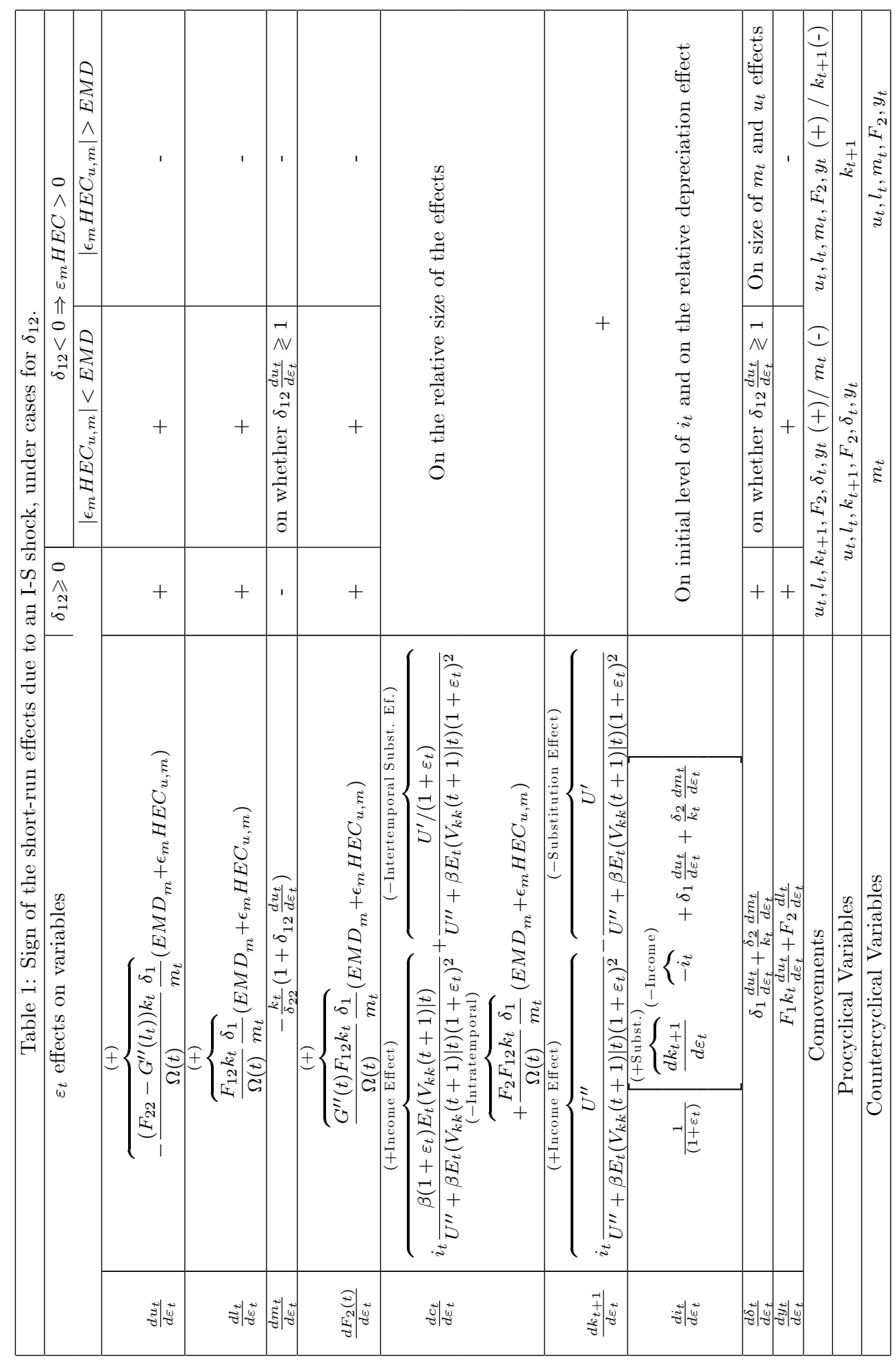




\begin{tabular}{|c|c|c|c|c|c|c|c|c|c|c|c|c|}
\hline 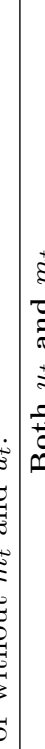 & 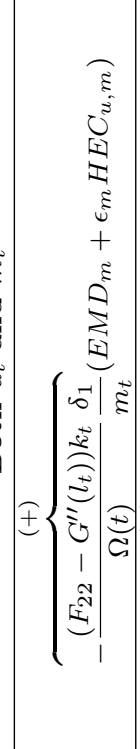 & 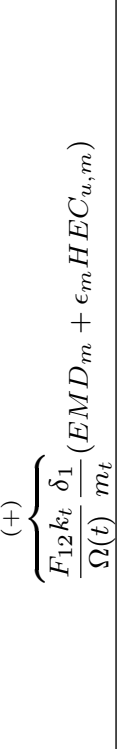 & 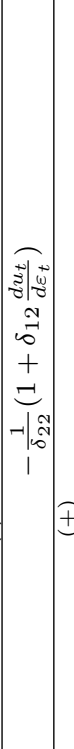 & 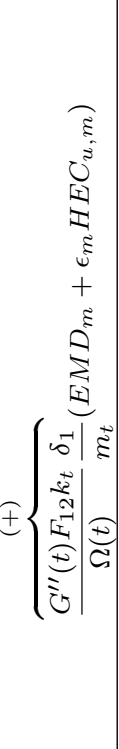 & 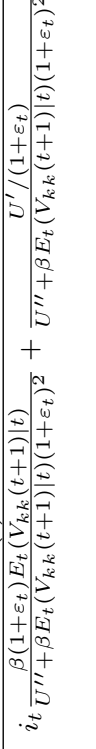 & 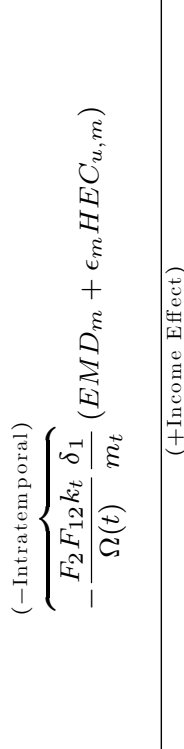 & 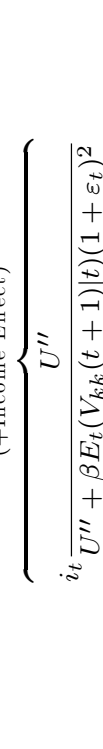 & 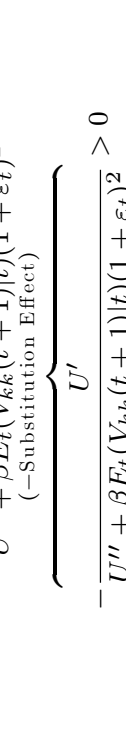 & 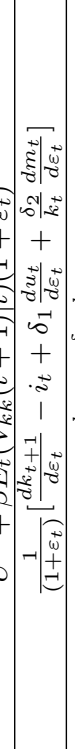 & 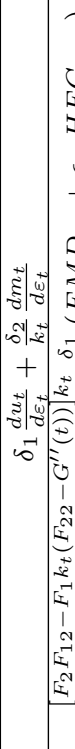 & 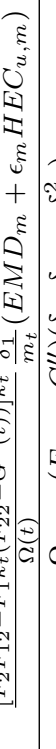 & 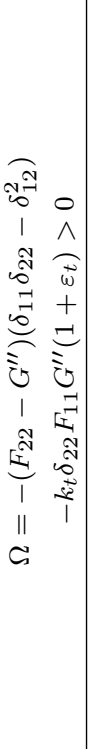 \\
\hline 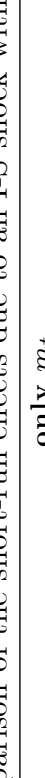 & & 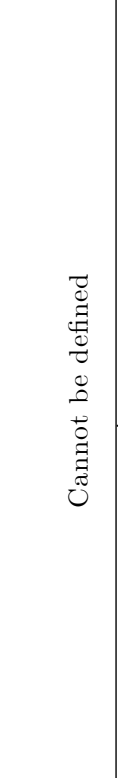 & 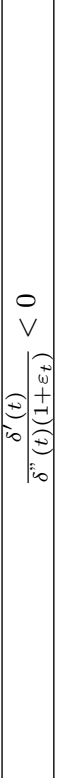 & 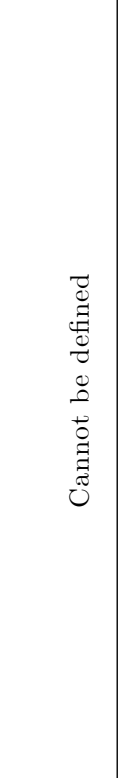 & 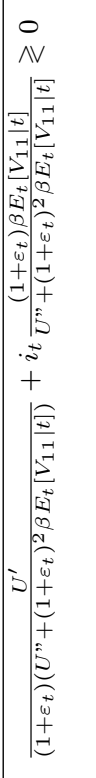 & 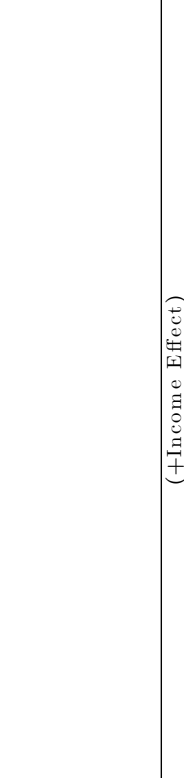 & 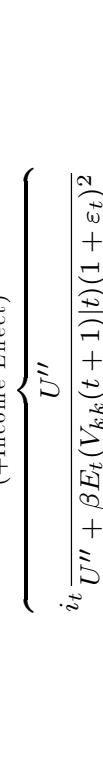 & 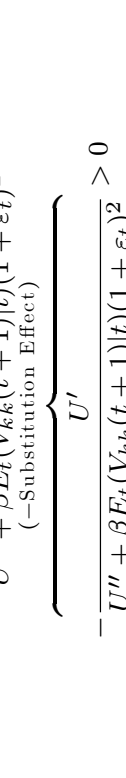 & 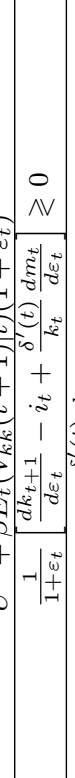 & 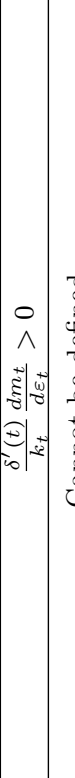 & 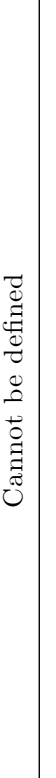 & \\
\hline va & 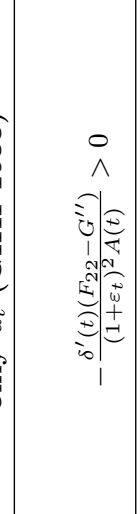 & 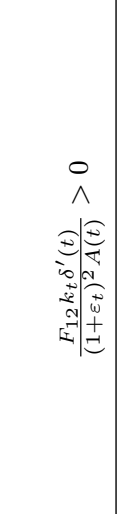 & & $\begin{array}{c}0 \\
\wedge \\
\vdots \\
0\end{array}$ & 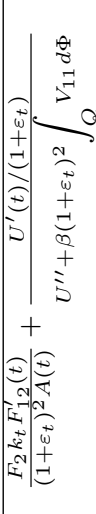 & 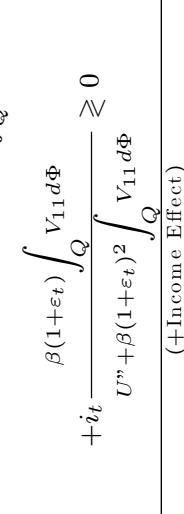 & 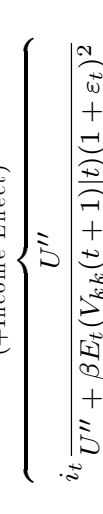 & 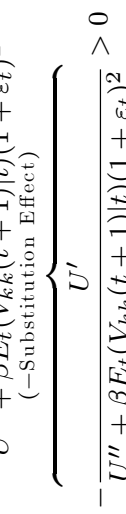 & 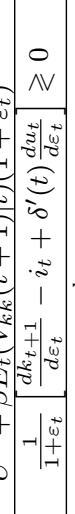 & 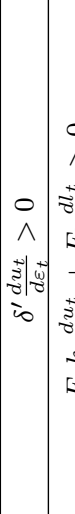 & . & 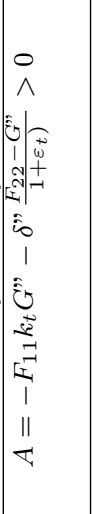 \\
\hline & 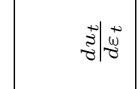 & 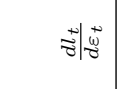 & 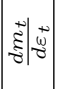 & 됳 & 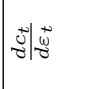 & & & & & & & $\vec{E}$ \\
\hline
\end{tabular}




\begin{tabular}{|c|c|c|c|c|c|c|c|c|c|c|c|}
\hline है & 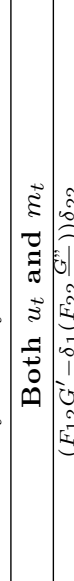 & \begin{tabular}{c|c} 
& \\
& \\
0
\end{tabular} & 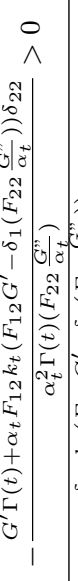 & 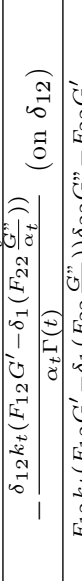 & 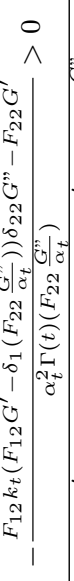 & 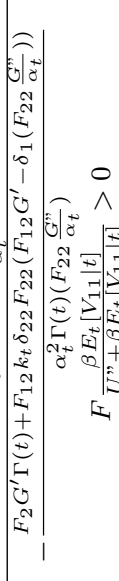 & 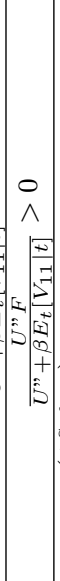 & 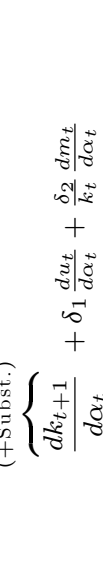 & 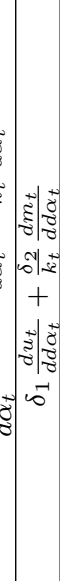 & 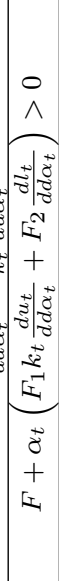 & 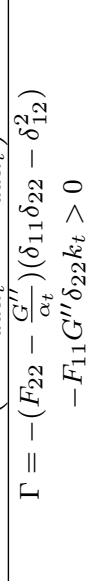 \\
\hline 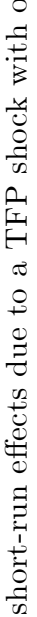 & 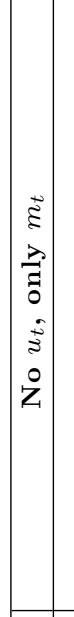 & & 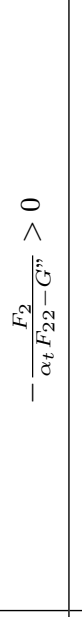 & 0 & 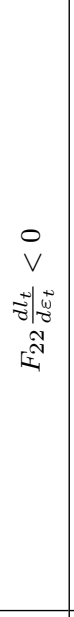 & 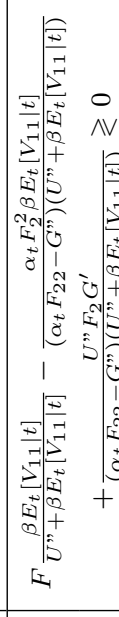 & 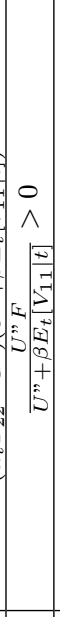 & 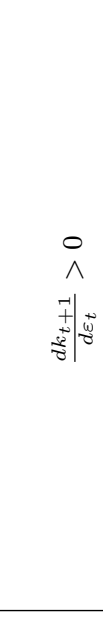 & 0 & 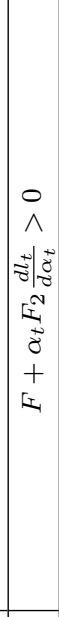 & \\
\hline 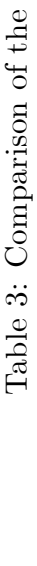 & $\mid$ & 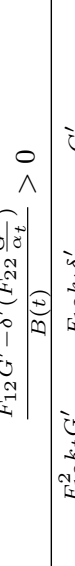 & 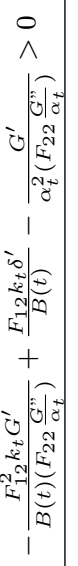 & & 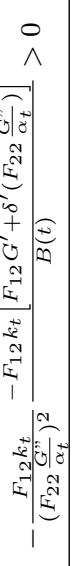 & 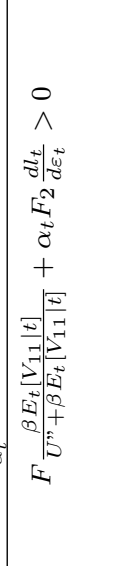 & 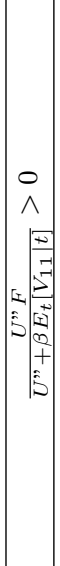 & 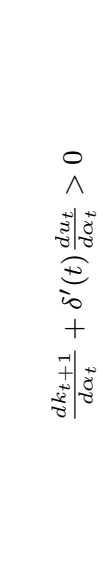 & 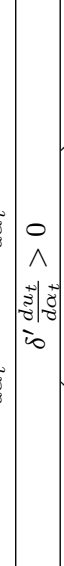 & 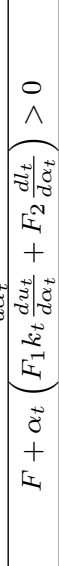 & 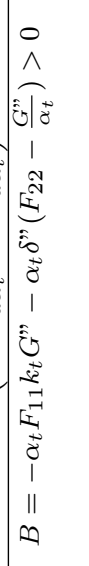 \\
\hline & & 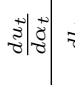 & चี & हैํㅎㅇ & 뙹 & 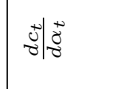 & & & & & 吾 \\
\hline
\end{tabular}




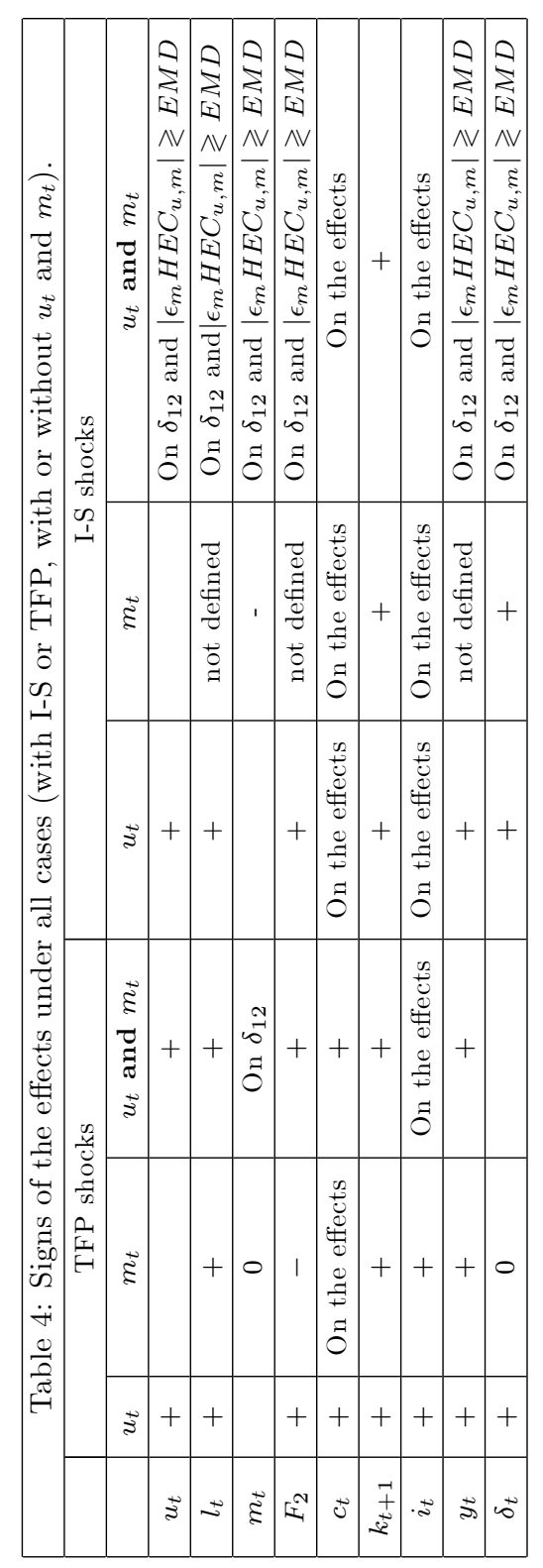




\section{A Appendix}

\section{A.1 The economy with a TFP shock}

We let the economy to be described by the same equations presented in section 3 , but now we suppose that only a TFP shock disturbs the economy. Therefore all the equations remain the same as in section 3 except from the capital accumulation equation (2) that now becomes:

$$
k_{t+1}=k_{t}\left[1-\delta\left(u_{t}, \frac{m_{t}}{k_{t}}\right)\right]+i_{t}
$$

The representative agent maximizes her expected lifetime utility by choosing next period's capital, labor, capital utilization, capital maintenance, and consumption. Let $V\left(k_{t} ; \alpha_{t}\right)$ be the value function that solves the maximization problem and assume that it exists, is unique, increasing, concave, and differentiable in its first argument. The stochastic Bellman equation is described by:

$$
\begin{aligned}
V\left(k_{t} ; \alpha_{t}\right) & =\max _{c_{t}, l_{t}, u_{t}, m_{t}, k_{t+1}}\left\{U\left(c_{t}, l_{t}\right)+\beta E_{t}\left[V\left(k_{t+1} ; \alpha_{t+1}\right)\right]\right\} \\
c_{t} & =\alpha_{t} F\left(u_{t} k_{t}, l_{t}\right)-m_{t}-k_{t+1}+k_{t}(1-\delta)
\end{aligned}
$$

The optimality conditions for this problem are given by:

[w.r.t. $\left.c_{t}\right]$ :

$$
U^{\prime}(t)=\beta E_{t}\left[V_{1}(t+1) \mid t\right]
$$

[w.r.t. $\left.u_{t}\right]$ :

$$
F_{1}=\frac{\delta_{1}}{\alpha_{t}}
$$

[w.r.t. $\left.l_{t}\right]$ :

$$
F_{2}=\frac{G^{\prime}(t)}{\alpha_{t}}
$$

[w.r.t. $\left.m_{t}\right]$ :

$$
\delta_{2}=-1
$$

\section{A.2 Derivation of the comparative statics: I-S shock}

We begin by considering the FOC for capital utilization (7). Totally differentiating for all the variables, apart from the state variable $k_{t}$ yields:

$$
\begin{aligned}
k_{t} F_{11} d u_{t}+F_{12} d l_{t} & =\frac{\delta_{11}}{1+\varepsilon_{t}} d u_{t}+\frac{\delta_{12}}{1+\varepsilon_{t}} \frac{1}{k_{t}} d m_{t}-\frac{\delta_{1}}{\left(1+\varepsilon_{t}\right)^{2}} d \varepsilon_{t} \stackrel{/ d \varepsilon_{t}}{\Rightarrow} \\
0 & =\left(k_{t} F_{11}-\frac{\delta_{11}}{1+\varepsilon_{t}}\right) \frac{d u_{t}}{d \varepsilon_{t}}+F_{12} \frac{d l_{t}}{d \varepsilon_{t}}-\frac{\delta_{12}}{1+\varepsilon_{t}} \frac{1}{k_{t}} \frac{d m_{t}}{d \varepsilon_{t}}+\frac{\delta_{1}}{\left(1+\varepsilon_{t}\right)^{2}}
\end{aligned}
$$


Similarly, from the FOC for labor (8) and the FOC for capital maintenance (9) we have:

$$
\begin{gathered}
F_{21} k_{t} \frac{d u_{t}}{d \varepsilon_{t}}+\left(F_{22}-G^{\prime \prime}\right) \frac{d l_{t}}{d \varepsilon_{t}}=0 \\
1+\delta_{21} \frac{d u_{t}}{d \varepsilon_{t}}+\delta_{22} \frac{d m_{t}}{d \varepsilon_{t}}=0
\end{gathered}
$$

Solving the system of equations (B.1)-(B.3.) for $\frac{d u_{t}}{d \varepsilon_{t}}, \frac{d l_{t}}{d \varepsilon_{t}}$, and $\frac{d m_{t}}{d \varepsilon_{t}}$ we get the equations for the responses for capital utilization, labor, and capital maintenance (11)-(13) respectively. In a similar way we proceed with the derivation of equations (14)-(18) provided in section 4.1.

\section{A.2.1 The Case $\delta_{12}<0$ and $\left|\epsilon_{m} H E C_{u, m}\right|=E M D_{m}$}

Under that case we have that $\frac{d u_{t}}{d \varepsilon_{t}}=0, \frac{d l_{t}}{d \varepsilon_{t}}=0, \frac{d m_{t}}{d \varepsilon_{t}}<0, \frac{d F_{2, t}}{d \varepsilon_{t}}=0, \frac{d c_{t}}{d \varepsilon_{t}} \gtrless 0, \frac{d i_{t}}{d \varepsilon_{t}} \gtrless 0, \frac{d \delta_{t}}{d \varepsilon_{t}} \gtrless 0$, and $\frac{d y_{t}}{d \varepsilon_{t}}=0$.

In this specific case it seems that the shock has no effect on capital utilization, labor, labor productivity, and output. In contrast, the effect of the shock on capital maintenance remains negative $\left(\frac{d m_{t}}{d \varepsilon_{t}}<0\right)$. The fact that maintenance is the only element of the model that is always affected by the shock has to do with our assumption that capital maintenance is independent from the labor choice.

\section{A.3 Dynamic effects of the shocks}

To assess the dynamic effects of an I-S shock (namely the long-run response of an I-S shock), it is assumed that $\varepsilon_{t}$ is serially uncorrelated. Hence, the next period's capital stock $k_{t+1}$ is the only channel that can generate persistence, which is assessed by considering the first-order conditions for capital utilization, labor, and capital maintenance expressed by equations (7)-(9) evaluated for one period ahead. Totally differentiating and solving a system of 3 equations and 3 unknowns yields:

$$
\begin{gathered}
\frac{d u_{t+1}}{d k_{t+1}}=\frac{\overbrace{\delta_{11}\left(F_{22}-G^{\prime \prime}\right)}^{(-)}+\overbrace{F_{11} u_{t+1} G^{\prime \prime}\left(1+\varepsilon_{t+1}\right)}^{\Omega(t+1)}}{\underbrace{(-)}_{(+)}}<0 \\
\frac{d l_{t+1}}{d k_{t+1}}=-\underbrace{\frac{F_{12}}{\left(F_{22}-G^{\prime \prime}\right)}}_{(-)}\left(u_{t+1}+k_{t+1} \frac{\left.d u_{t+1}\right)}{d k_{t+1}}\right) \\
\frac{d m_{t+1}}{d k_{t+1}}=\overbrace{\frac{m_{t+1}}{k_{t+1}}}^{(+)}-\underbrace{\delta_{12}^{\delta_{22}}}_{(+)} \frac{d u_{t+1}}{d k_{t+1}} \gtrless 0
\end{gathered}
$$


Given that $\Omega(t+1)>0$, and the assumptions made for the concavity of the production function and the capital depreciation function, equation (C.1.) implies that the optimal rate of utilization declines. This arises from the fact that a higher $k_{t+1}$ reduces the marginal productivity of capital services in period $t+1$. Equation (C.2.) shows the optimal flow of labor. No straight-forward results for the sign of this dynamic effect can be obtained, since it depends on the term $u_{t+1}+k_{t+1} \frac{d u_{t+1}}{d k_{t+1}}$. Therefore, it also depends on whether the value of capital utilization in period $t+1\left(u_{t+1}\right)$ is greater or not from the relative value of the next period's capital stock reduced by the negative long-run effect of capital utilization. Note that these dynamic effects are independent of the sign of the cross derivative $\delta_{12}$.

In contrast, the dynamic effect on capital maintenance expressed by equation (C.3.), is ambiguous. Equation (C.3.) suggests that under $\delta_{12} \geqslant 0$ the effect on maintenance is always positive, meaning that a higher $k_{t+1}$ increases the marginal productivity of capital services when they are maintained. On the other hand, when $\delta_{12}<0$, one has to examine whether the next period's maintenance to capital ratio $\left(\frac{m_{t+1}}{k_{t+1}}\right)$ is greater or not from the marginal dynamic effect on capital maintenance due to the change on capital utilization. When $\delta_{12}<0$ the dynamic effect on capital maintenance can be negative, meaning that a higher $k_{t+1}$ reduces the marginal productivity of capital services when maintained.

Moreover, the optimal flow of capital services $u_{t+1} k_{t+1}$ is expressed by:

$$
\frac{d u_{t+1} k_{t+1}}{d k_{t+1}}=u_{t+1}+k_{t+1} \frac{d u_{t+1}}{d k_{t+1}} \gtrless 0
$$

Total differentiation of the production function yields:

$$
\frac{d y_{t+1}}{d k_{t+1}}=\left(u_{t+1}+k_{t+1} \frac{d u_{t+1}}{d k_{t+1}}\right) \overbrace{\frac{F_{1}\left(F_{22}-G^{\prime \prime}\right)-F_{2} F_{12}}{\left(F_{22}-G^{\prime \prime}\right)}}^{(+)} \gtrless 0
$$

The direction of the dynamic effects on the optimal flow of capital services and on output, expressed by equations (C.4.) and (C.5.), is independent from the cross derivative $\delta_{12}$ and its sign depends on the term $u_{t+1}+k_{t+1} \frac{d u_{t+1}}{d k_{t+1}}$. Therefore, the dynamic effects of labor, optimal flow of capital services, and total output move always towards the same direction and have similar smoothing effects. Table 5 provides the dynamic effects under all cases for the sign of $\delta_{12}$.

\section{A.3.1 Persistence of the effects}

To examine the persistence of the I-S shock, the first-order condition for $k_{t+1}$ (given by equation 6 ) one period ahead is evaluated in line with Greenwood et al. (1988). Totally differentiating yields:

$$
\frac{d k_{t+2}}{d k_{t+1}}=\frac{U^{\prime \prime}(t+1)\left[F_{1} u_{t+1}\left(1+\varepsilon_{t+1}\right)+(1-\delta(t+1))\right.}{U^{\prime \prime}(t+1)+\left(1+\varepsilon_{t+1}\right)^{2} \beta E_{t+1}\left[V_{11}(t+2) \mid t+1\right]}>0
$$


This expression is positive and hence the effects will persist in future periods. To examine how the effects on the endogenous variables $u, l, m, u k$, and $y$ are affected in the future periods, it is assumed that they are expressed by policy functions of the form $x_{t+1}=x\left(k_{t+1}, \varepsilon_{t+1}\right)$. Taking the expected values of the derivatives of these functions with respect to next period's capital stock gives that $\frac{d E_{t}\left(x_{t+1}\right)}{d k_{t+1}}=E_{t}\left[\frac{d x_{t+1}}{d k_{t+1}}\right]$. The term $\frac{d x_{t+1}}{d k_{t+1}}$ reflects the dynamic effects of equations (C.1.)-(C.5.) for the variables $u, l, m, u k$, and $y$, respectively. Therefore, it can be seen for any period after the shock that all economic variables demonstrate persistent effects and in a similar fashion during the future periods, $t+2, \ldots$. 


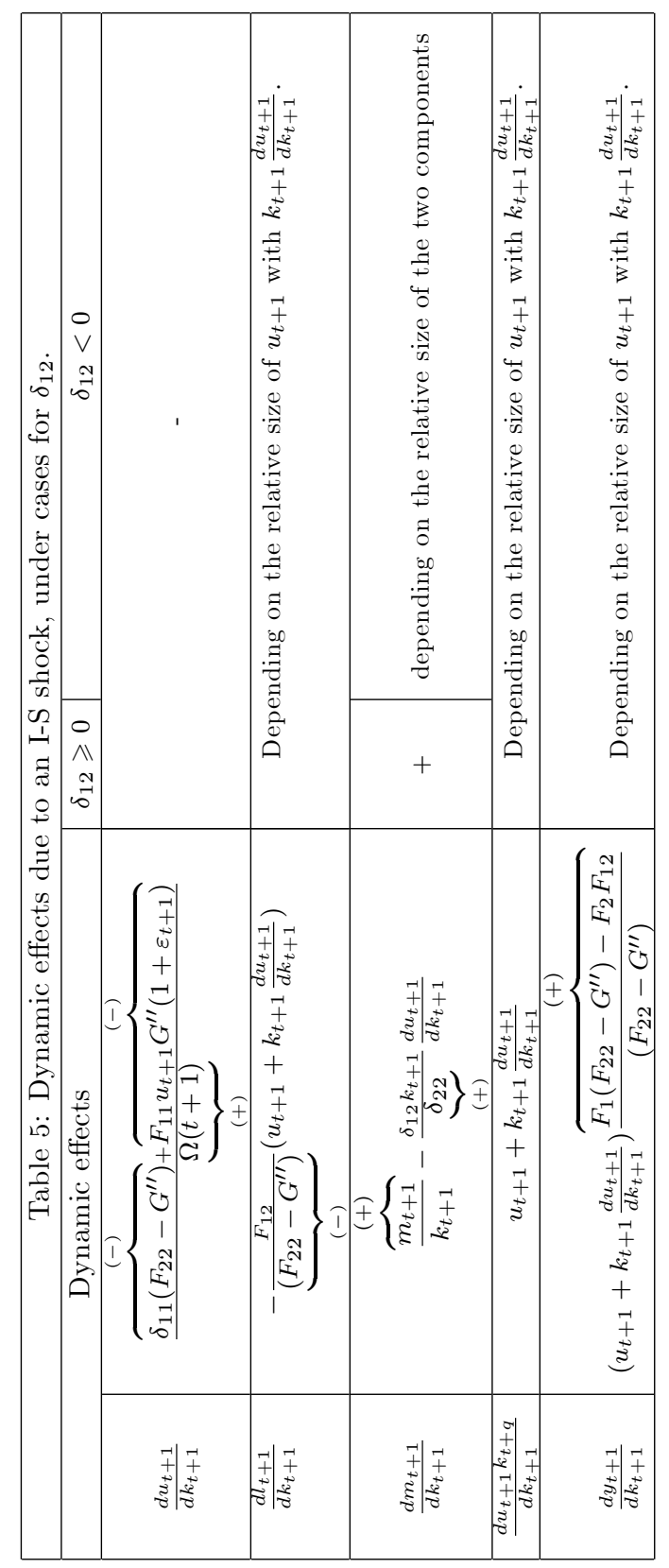

